\title{
Research on Estimation Method of Mileage Power Consumption for Electric Vehicles
}

\author{
Yang Xu and Kaiyu Wang* \\ Automotive Electronics and Embedded System Research Center, Chongqing University of Posts and Telecommunications, \\ Chongqing 400065, P. R. China \\ ${ }^{*}$ Corresponding author
}

\begin{abstract}
Accurate estimation of the power consumption of electric vehicles in the future driving route will help to reduce the user's range anxiety, which results from short all electric range of electric vehicles and the lack of charging facilities. The existing research methods mainly focus on three aspects: vehicle energy consumption, driving cycle identification and driving cycle prediction. In this paper, a method of estimating mileage power consumption based on driving cycle identification and prediction is proposed. Firstly, driving cycle categories and energy consumption of each category are obtained through conducting screening, sectioning, principal component analysis and fuzzy $\mathrm{C}$ clustering to the vehicle's historical operation data. Then, the future vehicle speed curve is predicted based on historical data, elevation information and real-time road congestion information, and the mileage consumption estimation model is established based on the identification and prediction of the driving cycle. Finally, 10 groups of real vehicle tests were carried out on the experimental vehicle. And the results showed that the average error between the estimated value of the mileage power consumption and the test value is $4.15 \%$, which met the requirements of the daily use of electric vehicles.
\end{abstract}

Keywords-electric vehicles; mileage power consumption estimation; driving cycle identification; driving cycle prediction

\section{INTRODUCTION}

Electric vehicle has attracted more and more attention due to its advantages of environmental protection, energy saving and intelligence. However, the majority of electric vehicle have short all electric range and fast charging facilities have not been widely popularized. Users will be worried that the existing electricity cannot guarantee the arrival of vehicles, and there is no timely charging facilities on the way, resulting in "mileage anxiety". Therefore, the accurate estimation of the power consumption between the destination and the destination is conducive to enhancing the user's confidence in the use of electric vehicles.

At present, most of the research focuses on the electric vehicle's remaining mileage, that is, how far the electric vehicle can run, and less about the estimation of the power consumption between the beginning and the destination specified by the user. There are three main aspects of the estimation of the remaining driving mileage: vehicle's energy consumption [1-3], driving cycle identification [4-7] and driving cycle prediction [8-10]. The method from the perspective of vehicle energy consumption focuses on the influence of vehicle driving parameters on the mileage. According to the principle of equal output energy and vehicle energy consumption, the vehicle's mileage is estimated.
In the estimation method of driving cycle recognition, the fragments of vehicle speed curve are divided into several types. And it is considered that the future energy consumption of vehicle is equal to the average energy consumption in the past period. The estimation method of driving cycle prediction is based on the driving cycle identification method and combines with the prediction of the driving cycle in the future, making a more accurate estimation. In this paper, a method of estimating mileage power consumption based on driving cycle identification and prediction is proposed is proposed. It aims at the actual demand for predicting power consumption (SOC changes) between the location and destination given by users. The diagram in Figure 1 represents the overall objective of this research.

The remaining of this paper is organized as follows. The cluster analysis of the driving cycle will be carried out in section II. In the section III, a vehicle speed curve prediction model will be discussed. In section IV, a estimation method of mileage power consumption will be discussed and validated following by some simulation results in section II and section III. Finally a conclusion will be made in section $\mathrm{V}$.

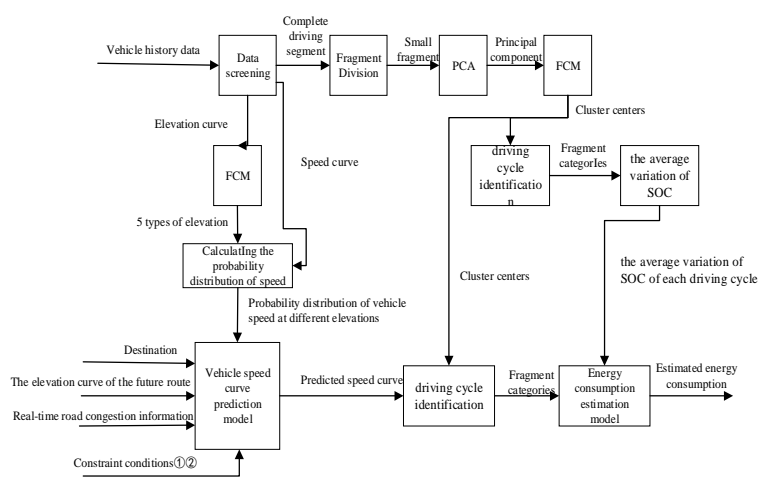

FIGURE I. BLOCK DIAGRAM OF THE ESTIMATION

METHOD OF MILEAGE POWER CONSUMPTION FOR ELECTRIC VEHICLES

\section{Cluster ANAlysis OF DRIVING CyCLE}

\section{A. Characteristic Parameters of the Driving Cycle Fragment}

Generally speaking, vehicle driving cycles is described by vehicle speed time curve. Typical driving cycles include UDDS operation in America, NEDC operation in Europe, and 10-15 working conditions in Japan. For extracting and analyzing the characteristic parameters of vehicle driving cycles, typical ECE15 driving cycle is used in [6]. In [7], the real driving data 
of the vehicle is used and divided according to the unit SOC in order to improving the accuracy. In this paper, not only the influence of vehicle speed and congestion on the vehicle energy consumption but also the influence of the change of lane's altitude on the vehicle energy consumption is considered. The speed curve and the GPS information is obtained in vehicle network monitoring platform. In the vehicle historical driving data, 30 complete driving processes were selected, which were divided into 718 driving cycle segments based on 120s. The data range covers the running data of the vehicle from June to December, 2016, and the running time was 8:00-22:00.

In order to accurately describe the characteristic information of vehicle speed curve, 12 characteristic parameters were identified in [6] and [7] to describe vehicle speed time curve in driving cycle segments which were also used in this paper as listed in Table 1.

TABLE I. THE CHARACTERISTIC PARAMETERS OF THE SPEED CURVE OF THE DRIVING CYCLE SEGMENT

\begin{tabular}{|c|c|c|c|}
\hline Parameter & Meaning & Parameter & Meaning \\
\hline$v_{\max }$ & The highest speed & $v_{s d}$ & $\begin{array}{c}\text { Standard deviation } \\
\text { of speed }\end{array}$ \\
\hline$v_{m}$ & Average speed & $A_{\max }$ & $\begin{array}{c}\text { Maximum } \\
\text { acceleration }\end{array}$ \\
\hline$P_{i}$ & Parking ratio & $A_{\min }$ & $\begin{array}{c}\text { Maximum } \\
\text { deceleration }\end{array}$ \\
\hline$v_{m r}$ & Running average speed & $P_{a}$ & Acceleration ratio \\
\hline$A_{a}$ & $\begin{array}{c}\text { Average acceleration of } \\
\text { acceleration section }\end{array}$ & $P_{d}$ & Deceleration ratio \\
\hline$A_{d}$ & $\begin{array}{c}\text { Average acceleration of } \\
\text { deceleration section }\end{array}$ & $P_{c}$ & $\begin{array}{c}\text { Uniform speed } \\
\text { ratio }\end{array}$ \\
\hline
\end{tabular}

For reducing the amount of calculation, the principal component analysis (PCA) of 12 parameters extracted from the vehicle running data was carried out in [6] and [7]. According to the principle of PCA [11], if the cumulative contribution rate of the former $\mathrm{k}$ principal components is above $80 \%$, the $\mathrm{k}$ principal components can be used to represent the original variables. After analyzing, 4 parameters which are highly correlated with the principal components are selected: the highest speed, average speed, parking ratio and average acceleration, as the characteristic parameters of fuzzy c-means (FCM) clustering algorithm.

\section{B. The FCM Analysis of the Driving Cycle Fragments}

The FCM algorithm [12] is an important branch of fuzzy pattern recognition. Its essence is to iterate and modify the cluster center and membership matrix to minimize the objective function value. Each element in K-means can only belongs to one category, while an element in the FCM belongs to each category with a different probability. Similar to K-means, the target function of FCM is as follows:

$$
J_{m}=\sum_{i=1}^{N} \sum_{j=1}^{C} u_{i j}^{m}\left\|x_{i}-c_{j}\right\|^{2}, 1 \leq m \leq \infty
$$

Where $m$ is a weighted index, $\left\|x_{i}-c_{j}\right\|^{2}$ is the distance between the ith data points and the cluster center of class jth and $u_{i j}$ is the degree of membership of the ith data point belonging to class jth, which is limited by: $0 \leq u_{i j} \leq 1, \sum_{i=1}^{C} u_{i j}=1$. The FCM aims at calculating the membership degree matrix $U$ and the cluster center matrix $\mathrm{C}$ to minimizing the object function $J_{m}$.
When the number of clusters $c=4$, the cluster centers are shown in Table 2. And parameters from left to right are: the highest speed, average speed, parking ratio and average acceleration.

TABLE II. CLUSTER CENTER OF 4 TYPES OF DRIVING CYCLES

\begin{tabular}{|c|c|c|}
\hline Categories & $\begin{array}{c}\text { Cluster centers after } 300 \\
\text { iterations }\end{array}$ & $\begin{array}{c}\text { Driving cycle } \\
\text { characteristics }\end{array}$ \\
\hline$C_{1}$ & $(12.618,5.287,0.446,-0.005)$ & $\begin{array}{c}\text { High parking ratio, low } \\
\text { speed }\end{array}$ \\
\hline$C_{2}$ & $(74.443,62.231,0.004,-0.014)$ & Smooth road, high speed \\
\hline$C_{3}$ & $(42.815,26.201,0.069,0.003)$ & $\begin{array}{c}\text { Medium parking ratio and } \\
\text { speed }\end{array}$ \\
\hline$C_{4}$ & $(59.385,48.532,0.004,0.003)$ & $\begin{array}{c}\text { A small number of } \\
\text { parking, medium speed }\end{array}$ \\
\hline
\end{tabular}

Consider the change in altitude alone and divide it into 5 classes. When the number of clusters $\mathrm{c}=5$, the cluster centers are shown in Table 3.

TABLE III. FIVE KINDS OF CLUSTER CENTERS FOR ALTITUDE CHANGE

\begin{tabular}{|c|c|c|}
\hline Categories & $\begin{array}{c}\text { Cluster centers } \\
\text { after } 300 \\
\text { iterations } \\
\end{array}$ & Elevation characteristics \\
\hline$C_{1}$ & -101.445 & $\begin{array}{c}\text { Middle elevation change, little steep } \\
\text { downhill }\end{array}$ \\
\hline$C_{2}$ & 45.463 & Small elevation change, flat road \\
\hline$C_{3}$ & -277.397 & $\begin{array}{c}\text { Large elevation change, steep } \\
\text { downhill }\end{array}$ \\
\hline$C_{4}$ & 199.818 & $\begin{array}{c}\text { Middle elevation change, little steep } \\
\text { uphill }\end{array}$ \\
\hline$C_{5}$ & 410.465 & Large elevation change, steep uphill \\
\hline
\end{tabular}

There will have 20 categories of driving cycles on the overall consideration of maximum speed, average speed, parking ratio, average acceleration and altitude change. The average variation of SOC in the 20 categories of driving cycles can be obtained by the formula (2):

$$
\overline{\Delta S O C_{l}}=\frac{\sum_{k=1}^{n_{i}} \Delta S O C_{k}}{n_{i}} ; i=1,2, \ldots, 20
$$

Where $\overline{\triangle S O C_{l}}$ is the SOC average variation of class ith, $n_{i}$ is the number of driving cycles in class ith and $\triangle S O C_{k}$ is the SOC variation of kth fragment in class ith.

According to formula (2), the average variation of SOC in the 20 categories of driving cycles are list in Table 4.

TABLE IV. VERAGE CHANGE OF SOC UNDER 20 TYPES OF DRIVING CYCLES

\begin{tabular}{|c|c|c|c|}
\hline categories & $\begin{array}{c}\text { the average variation } \\
\text { of SOC }\end{array}$ & categories & $\begin{array}{c}\text { the average } \\
\text { variation of SOC }\end{array}$ \\
\hline$C_{1}$ & 1.42131054 & $C_{11}$ & 1.20294766 \\
\hline$C_{2}$ & 1.52115799 & $C_{12}$ & 1.0206714 \\
\hline$C_{3}$ & 1.40876679 & $C_{13}$ & 0.66156447 \\
\hline$C_{4}$ & 1.3240051 & $C_{14}$ & 1.23478949 \\
\hline$C_{5}$ & 1.63209656 & $C_{15}$ & 1.23449078 \\
\hline$C_{6}$ & 1.3485119 & $C_{16}$ & 1.00145896 \\
\hline$C_{7}$ & 1.2146521 & $C_{17}$ & 1.46666667 \\
\hline$C_{8}$ & 1.06038662 & $C_{18}$ & 1.18666667 \\
\hline$C_{9}$ & 0.36728395 & $C_{19}$ & 0.95892833 \\
\hline$C_{10}$ & 1.47922074 & $C_{20}$ & 1.1 \\
\hline
\end{tabular}




\section{PREDiCATION OF SPEED CURVE BETWEEN ORIGIN AND DESTINATION}

\section{A. Prediction Method of Speed Curve between Two Place}

In this paper, vehicle's history driving data and future driving path information were used to forecasting the speed curve. From history driving data, vehicle's speed probability distribution in different elevation were extracted, and future driving path information includes elevation curve and real time traffic jam level. Figure 3 shows the framework of the predication method, and the specific procedure is explained as follows:

- According to the destination set by user, the future driving path between origin and destination is acquired from Omni range system like google maps. Based on this, information including elevation curve and real time traffic jam can be extracted in the same time.

- $\quad$ Splitting the total driving path into path segments per 50 meters, and computing the elevation change level of every segment. according to speed distribution of different elevation change level and the constrain condition proposed later, the speed cure could be generated randomly in every path segment.

- $\quad$ Finally, total future driving path's speed curve can be acquired by combing the path segments' speed curve.

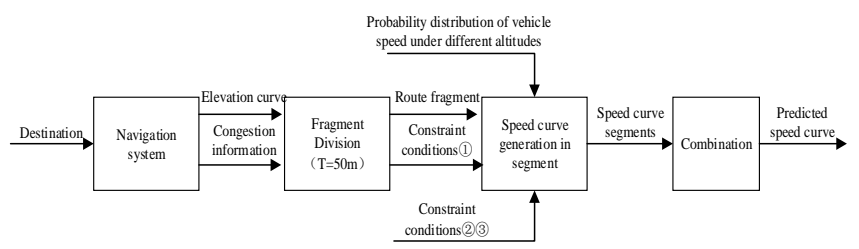

FIGURE II.

\section{VEHICLE SPEED CURVE PREDICTION} MODEL

\section{B. Constrain Condition}

As indicated above, there are three constrain condition in the vehicle speed curve prediction model, they are explained in follow:

- Real time traffic jam constrains. According to Evaluation Index System of Urban Road Traffic Management announced by Chinese ministry of public security in 2002, the average speed is used to determinate traffic jam level. In [13], average speed is chosen as traffic jam level evaluation index preferentially. If it is absence, the amount and density of vehicle will be alternative. According to China and some other country's index, the speed thresholds for different traffic jam level are determined and the result is shown in Table 5 . Accordingly, the speed range of every segment, which can be obtained after getting realtime road congestion information, can be as one of the constrain conditions for generating speed curve.
TABLE V. DETERMINATION OF TRAFFIC CONGESTION LEVEL IN ACTUAL ROAD CONDITIONS

\begin{tabular}{|c|c|c|c|}
\hline $\begin{array}{c}\text { Congestion } \\
\text { level }\end{array}$ & $\begin{array}{c}\text { speed } \\
/(\mathbf{k m} \cdot \mathbf{h}-\mathbf{1})\end{array}$ & $\begin{array}{c}\text { Vehicle } \\
\text { flow/(car-min-1) }\end{array}$ & $\begin{array}{c}\text { traffic density } \\
/ \text { (car-m-1) }\end{array}$ \\
\hline Smooth & $\mathrm{v} \geq 30$ & $\mathrm{q} \leq 60$ & $\mathrm{k} \leq 0.5$ \\
\hline amble & $20 \leq \mathrm{v}<30$ & $60<\mathrm{q} \leq 90$ & $0.5<\mathrm{k} \leq 0.75$ \\
\hline congestion & $10 \leq \mathrm{v}<20$ & $40 \leq \mathrm{q}<60$ & $0.75<\mathrm{k} \leq 0.9$ \\
\hline $\begin{array}{c}\text { severe } \\
\text { congestion }\end{array}$ & $\mathrm{v}<10$ & $\mathrm{q}<40$ & $\mathrm{q}>0.9$ \\
\hline
\end{tabular}

- Integral on generated speed curve’s must equals to actual mileage of segment. as what mentioned before, path segment's mileage is 50 meters, so the equation (3) must be satisfied on every segment.

$$
\mathrm{S}=\sum_{k=0}^{t_{i}} v(k) \cdot T=50
$$

Where $\mathrm{S}$ is driving mileage and $t_{i}$ is driving time of the $i$ th path segment. $T$ is the time serial's step value which is 1 second, $v(k)$ indicates spend of kth moment.

- $\quad$ The rate of speed change should under a constrain level. It is a basic fact that the speed change of vehicle in a determined step value should under a threshold which is make sense, and the threshold is extracted from history data:

$$
0 \leq \Delta \leq 2.8
$$

Where $\Delta$ indicates the threshold.

\section{EVAluAtion METHOD OF ENERGy CONSUMPTION BETWEEN ORIGIN AND DESTINATION AND VERIFICATION}

A. Evaluation Method of Energy Consumption between Origin and Destination

The proposed evaluation method's procedures is shown at Figure IV, there are mainly 4 steps in this method:

- $\quad$ Splitting the predicated speed curve of future driving path into $n$ segments by invariable time interval, which is 120 seconds in this paper. Then the 4 feature parameter can be computed.

- Elevation change curve between two places should be acquired by GPS, then the absolute change value can be extracted from the curve.

- Computing the distances of target segment to 20 clustered centers. Base on nearest neighbor principle determine which category the target segment is belong to. The distance's calculation formula is (5):

$$
d_{i}=\sqrt{\sum_{k=1}^{5}\left(x_{k}-c_{i k}\right)^{2}} ; i=1,2, \ldots, 20
$$

Where $d_{i}$ is the distance between target segment and the $i$ th segment, $x_{k}$ is $k$ th feature parameter value of target segment, $c_{i k}$ is value of $k$ th feature parameter of $i$ th driving cycle center. 
- After identifying the category of the fragment, the energy consumption between the destination and the destination is calculated by the formula (6):

$$
S O C_{c o s}=\sum_{i=1}^{n} \Delta S O C_{i}
$$

Where $S O C_{\text {cos }}$ is the estimated energy consumption and $\triangle S O C_{i}$ is the SOC variation of each fragment.

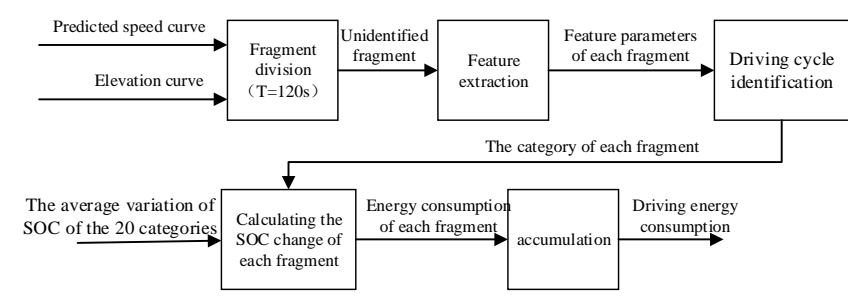

FIGURE III. ESTIMATION METHOD OF VEHICLE ENERGY CONSUMPTION BETWEEN STARTING AND DESTINATION

\section{B. 4.2 Verification of the Method}

In order to verify the accuracy and universality of the estimation method of vehicle energy consumption, 10 groups of tests were carried out for different elevation changes, number of corners and road congestion. The evaluation index is the absolute error between the estimated value and the actual value.

$$
S O C_{d e v}=\left|S O C_{e v}-S O C_{r e l}\right|
$$

The 10 sets of test results and errors are shown in Table 6.

\begin{tabular}{|c|c|c|c|c|c|}
\hline Order & $\begin{array}{c}\text { The } \\
\text { proportion of } \\
\text { smooth, } \\
\text { amble, } \\
\text { congestion, } \\
\text { severe } \\
\text { congestion(\%) }\end{array}$ & $\begin{array}{l}\text { Elevation, } \\
\text { bend }\end{array}$ & $\begin{array}{c}\text { The } \\
\text { estimat } \\
\text { ed } \\
\text { value } \\
(\%)\end{array}$ & $\begin{array}{c}\text { The } \\
\text { actual } \\
\text { value } \\
\text { (\%) }\end{array}$ & $\begin{array}{l}\text { The } \\
\text { absolute } \\
\text { error } \\
\text { (\%) }\end{array}$ \\
\hline 1 & $(85,7,4,4)$ & flat & 35.20 & 35.33 & 0.13 \\
\hline 2 & $(88,3,2,7)$ & a bit flat & 78.84 & 78.32 & 0.52 \\
\hline 3 & $(100,0,0,0)$ & $\begin{array}{l}\text { Small change } \\
\text { in elevation }\end{array}$ & 37.81 & 38.90 & 1.09 \\
\hline 4 & $(80,13,7,0)$ & $\begin{array}{c}\text { Small change } \\
\text { in elevation }\end{array}$ & 55.32 & 52.68 & 2.64 \\
\hline 5 & $(86,7,3,4)$ & $\begin{array}{l}\text { Small change } \\
\text { in elevation } \\
\text { and less } \\
\text { bends }\end{array}$ & 37.32 & 34.53 & 2.79 \\
\hline 6 & $(86,2,10,2)$ & $\begin{array}{c}\text { Middle } \\
\text { change in } \\
\text { elevation }\end{array}$ & 54.54 & 58.6 & 4.06 \\
\hline 7 & $(92,0,0,8)$ & $\begin{array}{l}\text { Large change } \\
\text { in elevation }\end{array}$ & 78.91 & 83.83 & 4.92 \\
\hline 8 & $(55,22,16,7)$ & $\begin{array}{l}\text { Small change } \\
\text { in elevation }\end{array}$ & 34.7 & 26.72 & 7.98 \\
\hline 9 & $(70,21,6,3)$ & $\begin{array}{c}\text { Middle } \\
\text { change in } \\
\text { elevation, } \\
\text { more bends }\end{array}$ & 36.75 & 28.76 & 7.99 \\
\hline 10 & $(87,2,4,6)$ & $\begin{array}{l}\text { Large change } \\
\text { in elevation, a } \\
\text { lot of bends }\end{array}$ & 51.3 & 41.88 & 9.42 \\
\hline
\end{tabular}

TABLE VI. THE TEST RESULTS
According to Table 6, when the road is flat or the elevation changes little, the algorithm's errors are less than $5 \%$. When road congestion is serious (the 8th groups) or elevation (the 9th group), the error increases slightly. Due to the lack of consideration on the impact of bends to speed and energy consumption, due to no consideration of the impact of the curve on the speed and energy consumption, the error will also increase in the bend road.

\section{CONCLUSIONS}

In this paper, a method of estimating mileage power consumption based on driving cycle identification and prediction is proposed is proposed. It aims at the actual demand for predicting power consumption (SOC changes) between the location and destination given by users. In the driving cycle identification, the PCA and FCM are used to analyze the vehicle history data and then classify the driving cycle. In the driving cycle prediction, combining with the probability distribution of speed at different altitudes under the historical data, real-time traffic congestion information and other two constraints, the future route speed curve is predicted, achieving the prediction of future driving cycles. Finally, the feasibility of the estimation method of electric vehicle mileage consumption based on driving cycle identification and prediction is verified by 10 groups of tests.

\section{ACKNOWLEDGMENT}

The authors would like to thank Automotive Electronics and Embedded System Research center for all fruitful group discussions and feedbacks. This project is financially supported by the Doctoral Scientific Research Foundation of Chongqing University of Posts and Telecommunications, and the project number is A2017-134.

\section{REFERENCES}

[1] C. H. Lee and C. H. Wu, "A novel big data modeling method for improving driving range estimation of EVs," in IEEE Access, vol. 3, pp. 1980-1993, 2015.

[2] N. Chang, D. Baek and J. Hong, "Power consumption characterization, modeling and estimation of electric vehicles," 2014 IEEE/ACM International Conference on Computer-Aided Design (ICCAD), San Jose, CA, 2014, pp. 175-182.

[3] J. Hong, S. Park and N. Chang, "Accurate remaining range estimation for Electric vehicles," 2016 21st Asia and South Pacific Design Automation Conference (ASP-DAC), Macau, 2016, pp. 781-786.

[4] H. Yu, F. Tseng and R. McGee, "Driving pattern identification for EV range estimation," 2012 IEEE International Electric Vehicle Conference, Greenville, SC, 2012, pp. 1-7.

[5] Q. Gong, S. Midlam-Mohler, V. Marano, G. Rizzoni and Y. Guezennec, "Statistical analysis of PHEV fleet data," 2010 IEEE Vehicle Power and Propulsion Conference, Lille, 2010, pp. 1-6.

[6] A. D. Yin, H. Zhao, B. Zhou, "Driving range estimation for battery electric vehicles based on driving cycle identification," in Automotive Engineering, vol. 11, pp. 1310-1315, 2014.

[7] J. Lian, A. N. Zheng, Y. F. Zhou, "Driving range estimation for electric vehicles based on battery state of charge and driving cycle identification," in Science Technology \& Engineering, vol. 16, no. 16, pp. 113-117,2016.

[8] G. M. Liu, M. G. Ouyang, L. G. Lu, "Driving range estimation for electric vehicles based on battery energy state estimation and vehicle energy consumption prediction," in Automotive Engineering, vol. 11, pp. 1302$1309,2014$.

[9] J. A. Oliva, C. Weihrauch and T. Bertram, "Model-based remaining driving range prediction in electric vehicles by using particle filtering and 
Markov chains," 2013 World Electric Vehicle Symposium and Exhibition (EVS27), Barcelona, 2013, pp. 1-10.

[10] F. A. Bender, M. Kaszynski and O. Sawodny, "Drive Cycle Prediction and Energy Management Optimization for Hybrid Hydraulic Vehicles," in IEEE Transactions on Vehicular Technology, vol. 62, no. 8, pp. 35813592, Oct. 2013.

[11] J. W. Han, K. Micheline, P. Jian, Data mining concepts and techniques, 3rd ed., Singapore: Elsevier, 2012, pp. 67.

[12] X. Q. He, Multivariate statistical analysis multivariate statistical analysis 2nd ed., Beijing: China Renmin University Press, 2008, pp.189.

[13] T. T. Yang, X. Li, "Accuracy assessment of real-time road status system based on multi-original data," in Journal of Jiangsu Normal University: Natural Science ed., vol.3, no. 34, pp. 65-69, 2016. 